\title{
On the internal boundary layer related wind stress curl and its role in generating shallow lake circulations
}

\author{
János Józsa
}

Budapest University of Technology and Economics, Department of Hydraulic and Water Resources Engineering, also MTA-BME Water Management Research Group, Műegyetem rkp 3, H-1111, Budapest, Hungary. E-mail: jozsa@vit.bme.hu

\begin{abstract}
The paper demonstrates that the wind stress curl as an external vorticity source plays an important role in shaping large scale shallow lake circulations. The analysis of purpose-oriented simultaneous wind and current measurements data from the Hungarian part of Lake Neusiedl reasonably fits well the internal boundary layer development theory over the lake surface. A 2-D vorticity formulation of wind-induced flows is used to demonstrate mathematically the IBL-related large scale circulation generation mechanism well reflected in the measured data. Further validation of the findings is carried out by means of simple 2-D numerical flow modelling, in which details on the flow pattern besides the measurement sites could be also revealed. Wind-induced lake circulations linked to IBL development shows a novelty to be implemented in up-to-date numerical flow models.
\end{abstract}

Keywords: Wind-induced flow; Internal boundary layer; Wind stress curl; Shallow lakes; Lake Neusiedl.

\section{INTRODUCTION}

Shallow lakes with their unique value have received enhanced attention all over the world. While their multi-purpose utilization has been more and more recognised, it has occasionally led to misuse them thus worsening their ecological state. In addition, climate change, at least the fact that the frequency and/or the magnitude of extremes seem to grow, change also the boundary conditions for these vulnerable water bodies. In spite of this, efforts put in lake studies are still quite moderate compared to maritime research and major projects often focus on deep lakes only. When trying to adapt the findings in deep lakes to the shallow ones, one has to cope then with a number of problems due to the differences in the prevailing time and space scales. In fact, shallow lakes have got their own features and need special research and management methodology.

\section{WATER MOTION IN SHALLOW LAKES}

Flows in shallow lakes are predominantly induced by the wind. Part of the momentum of the wind over the lake is transferred into the water through the lake surface to generate waves, turbulence, large scale circulations and oscillatory motion called seiche, but also secondary currents like e.g. the Langmuir circulations. This momentum flux drives then the sediment strirring-up at the lake bottom, the mixing in the water body, and the interaction between the littoral and pelagic zones. In general, the shallower the lake, the more efficient is the influence of the external surface forces on the bottom. Surface waves generated even by moderate winds can induce shear stress at the bottom and stir up the uppermost sediment layer of the lake bed. While kept in resuspension by turbulence, particles can be transported by advective currents over large distances and settle if local conditions promote it. Another consequence of shallowness is that wind-induced turbulence can easily destroy temperature stratification, thus making the lake thermally homogenous.
The largest scale wind-induced lake motions are the oscillatory (seiche) and circulatory currents. Looking at their water exchange impact, oscillations in themselves usually would not result in significant net exchange, but accompanied by windinduced circulations their combined influence is significantly enhanced. Circulations are induced by the surface wind shear stress field and shaped by various factors. Though always threedimensional to some extent, they very often show organised horizontal flow pattern consisting of large-scale gyres. In fact, circulations to be generated and maintained need vorticity sources. Such sources can be originated e.g. from depth gradients (Simons, 1980), irregular wind field (Curto et al., 2006; Józsa et al., 1998; Józsa et al., 1990; Laval et al., 2003; Rueda et al., 2005; Schwab and Beletsky, 2003), irregular lake surface exposure to the wind due to lakeshore forest (Podsetchine and Schernewski, 1999), emergent littoral zone vegetation (Józsa et al., 1999; Sarkkula et al., 1991) or indirectly from the earth rotation itself (Simons, 1980).

Windstorms can easily generate lake-wide circulations with $10-20 \mathrm{~cm} / \mathrm{s}$ flow velocity, which if sustained e.g. for half day, may result in significant, several km long net horizontal advection. In most shallow lakes it is comparable with their horizontal extension consequently such circulations with sufficient duration, stability and return frequency usually dominate the lake-wide exchange of water masses and all the substances carried by them.

The primary goal of the present paper is to discuss and prove the importance of wind stress curl as an external vorticity source in generating large scale lake circulations. In doing so, we will analyse purpose-oriented simultaneous wind and current measurements performed in the Hungarian part of Lake Neusiedl, overview the theory of the so-called atmospheric Internal Boundary Layer (hereafter IBL) development over the lake surface, reconstruct its features for the study bay based on the collected data, mathematically demonstrate the role of IBLrelated wind stress curl in generating large scale horizontal circulations, and validate all that with simple 2-D numerical flow modelling. 


\section{LAKE NEUSIEDL AS CASE STUDY AREA}

In the rather flat Carpathian Basin Lake Balaton, the largest shallow lake in Central Europe, and Lake Neusiedl (Fertő in Hungarian), the westernmost large steppe lake in Europe are among the most important shallow surface waters. In the present paper, to discuss wind-induced hydrodynamic features, Lake Neusiedl will be looked at as a case study area. In the lake, the average depth of the pelagic area is less than $2 \mathrm{~m}$ whereas in the reed-covered zones, occupying more than half of the lake surface, the average depth is less than half a meter (Fig. 1). The bottom is very flat and mild-sloped both in the pelagic areas and in the littoral zones, which, as will be seen later in this paper, will give a pronounced role to the spatial irregularities of the surface wind shear stress field to generate large circulations. The lakebed is muddy with strong siltation tendencies at places, except in regions strongly exposed to waves. Water exchange between the pelagic and littoral zones is often poor occasionally resulting in reed quality deterioration. The lake is part of a joint national park shared by Austria and Hungary. Furthermore, due to its uniqueness the lake became a member of the World Heritage Sites in the beginning of the millennium.

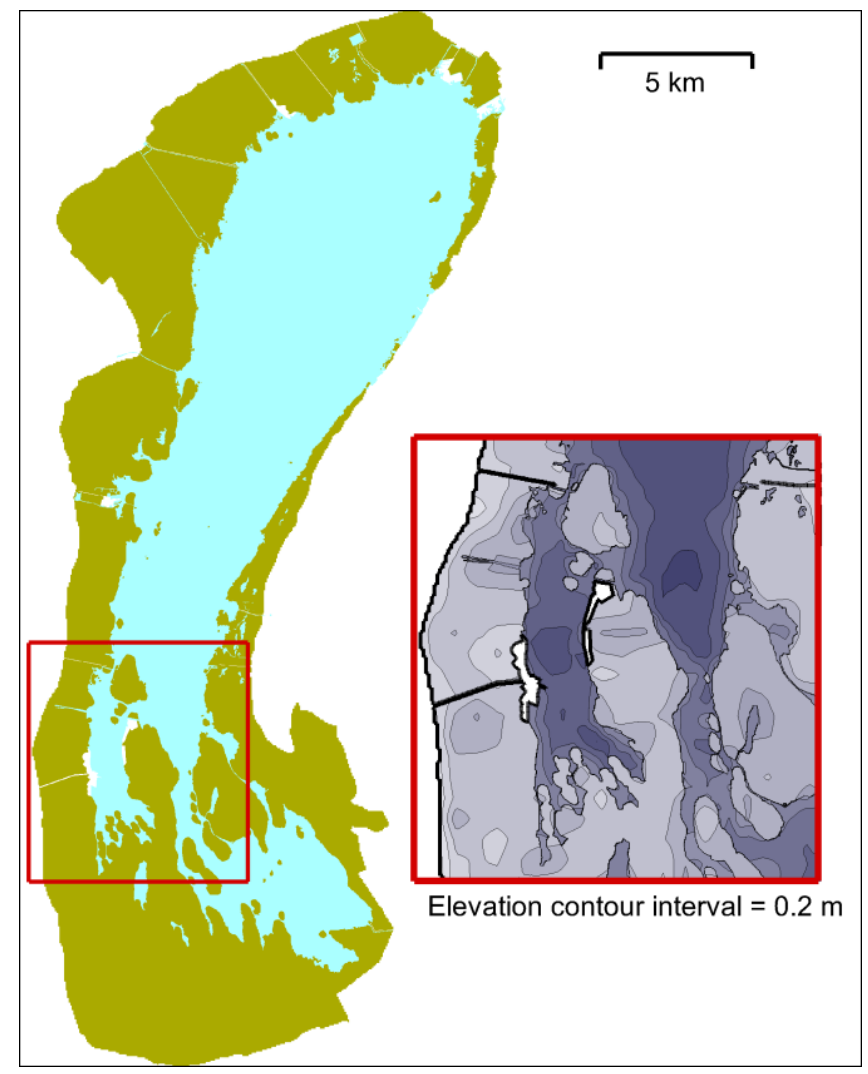

Fig. 1. Layout of Lake Neusiedl with its complex littoral reed belt and pelagic waters. Right panel: zooming on in Fertőrákos Bay bed elevation.

\section{On the past hydrodynamic research}

In addition to the traditional hydro-meteorological observations, baseline hydrodynamic explorations started long ago in both Austria and Hungary investigating the wind-induced seiche and circulatory motion and looking for possible reasons for unfavourable silting-up in some parts of the lake. Field measurement campaigns carried out using an instrumentation of their epoch in the sixties, seventies and early eighties provided significant results, except to the water currents on which data only with very limited value could be collected due to lacking technology. This was an obstacle for a while also for validating numerical flow models developed since the early eighties.

Luckily, in the late seventies the Norwegian Aanderaa recording current meters, meant originally for sea conditions, were successfully applied in Finland in shallow lakes, giving a significant impulse to lake hydrodynamic research also in Austria and Hungary in various cooperation frameworks. A number of projects on bi- and trilateral bases have been established since the mid-eighties with a significant Finnish contribution, leading to a number of fruitful joint research programmes and methodological development.

In the nineties and at the turn of the century in the Hungarian part of the lake, the focus was on Fertorrákos Bay (Fig. 1). The first results were summarised by Sarkkula et al. (1991), whereas the achievements of the mid-nineties were published by Józsa et al. (1998) and Józsa et al. (1999).

\section{Dual point wind and flow measurements}

In 2001 a special measurement campaign was conceived and carried out in Fertörákos Bay (Fig. 1, right panel) in order to explore the irregularities, to be more specific, the inherent structure of the wind field over the lake surface, considered as a key factor to shape the horizontal circulations patterns. The results and their evaluation have been published in various research reports, whereas the main findings with complete and reasonable generalisation will be for the first time discussed here.

However, before doing so, let us overview the up-to-date knowledge on the main features of wind and wind stress fields over lake surfaces with particular attention onto the formation of internal boundary layer due to the abrupt change (either landto-water or water-to-land) in the surface roughness height. Compared to available literature, (Laval et al., 2003; Podsetchine and Schernewski, 1999; Rueda et al., 2005; Simons, 1980; Schwab and Beletsky, 2003) it is in fact a novelty to link wind-induced lake circulations to IBL development, verified by field measurement, explained by theory and validated by numerical modelling.

\section{NEAR-SURFACE WIND A WIND SHEAR STRESS}

In the absence of large-scale upwind topographic features and for lakes with horizontal extension up to some tens of kilometres, the wind speed field over the lake is still often considered spatially constant, and efforts are usually put then on determining the wind speed-dependent lake surface roughness only. However, in reality, the IBL development over the lake surface due to the abrupt change in roughness conditions at the shore- or reed borderline results in significant modification of the near-surface wind profile along the fetch. Since the air-towater momentum flux is governed by the wind shear stress at the water surface, the development of the IBL is expected to have significant impact on the lake circulation patterns.

\section{Near-surface wind profile}

With neutral thermal stratification (that is air and water temperature being fairly identical to each other at the interface), the vertical distribution of the near-surface horizontal wind speed $\mathrm{W}(\mathrm{z})$ in terms of the height $\mathrm{z}$ above the lake surface obeys the 
well-known logarithmic law as given e.g. by Stull (1991) used also in river turbulent boundary-layer approximations (see e.g. Rao and Kumar, 2008):

$W(z)=\frac{W_{*}}{\kappa} \ln \frac{z}{z_{0}}$,

where $W_{*}$ - friction velocity; $\kappa=0.4-$ von Kármán constant; $z_{0}$ - aerodynamic roughness height of the water surface. It is thus possible to transform wind data measured at a height $z_{a}$ to the customary reference height of $10 \mathrm{~m}$ as follows:

$$
W_{10}(0)=W_{z_{a}}(0) \frac{\ln \frac{10}{z_{0}}}{\ln \frac{z_{a}}{z_{0}}} \text {. }
$$

A widely excepted estimation of the roughness height $z_{0}$ of the wavy water surface can be obtained by the formula proposed by Charnock (1955):

$z_{0}=\alpha \frac{W_{*}^{2}}{g}$,

where $\alpha=0.0185(\mathrm{Wu}, 1982), g-$ acceleration due to gravity.

With the abovementioned relationships, the $\tau_{s}$ surface wind shear stress scaling the momentum transfer from air to water can be expressed as:

$\tau_{\mathrm{s}} \equiv \rho_{\mathrm{a}} W_{*}^{2}=\rho_{a} c_{10} W_{10}^{2}=\rho_{\mathrm{a}} \frac{\kappa^{2}}{\left(\ln \frac{10}{z_{0}}\right)^{2}} W_{10}^{2}$,

where $\rho_{\mathrm{a}}-$ air density, $c_{10}-$ aerodynamic drag coefficient related to the wind speed at $10 \mathrm{~m}$.

\section{IBL theory and its implementation for the lake surface}

As an abrupt change of several orders of magnitude drop (from $10^{-1}$ to $10^{-3}-10^{-4} \mathrm{~m}$ ) occurs in the aerodynamic roughness conditions at the lakeshore or reed borderline, it clearly results in the downwind development of an IBL over the lake as sketched in Fig. 2 in a semi-logarithmic display. If there is no temperature stratification then the IBL is caused purely by mechanics reasons mechanical reasons (Stull, 1991). The semianalytical description of IBL development has been discussed for a long time in boundary-layer meteorology but mainly as land-to-land transition with sudden roughness change (Elliott, 1958; Savelyev and Taylor, 2001; Taylor and Lee, 1984; Walmsley, 1989). Here, the general description given by Taylor and Lee (1984) using the generic idea of Elliott (1958) is followed, according to which the IBL height $\delta_{\mathrm{b}}$ is governed mainly by two parameters, the fetch $F$ and the lake surface roughness height $z_{0,2}$ as

$\delta_{\mathrm{b}}(F)=0.75 z_{0.2}\left(\frac{F}{z_{0,2}}\right)^{0.8}$,

where the lake surface roughness is also a function of the fetch, as seen later.

As a result of this gradual growth, the vertical profile of the horizontal wind speed consists of two parts: outside the IBL, the profile is still assumed to be identical with the one at the shoreline, simply expressed by

$\delta_{\mathrm{b}}(F) \leq z: \quad W_{z}(F)=W_{z}(0)$, whereas within the IBL, the wind speed is determined by the formula

$\delta_{\mathrm{b}}(F)>z: \quad W_{z}(F)=W_{z}(0) \frac{\ln \frac{z}{z_{0,2}} \ln \frac{\delta_{\mathrm{b}}(F)}{z_{0,1}}}{\ln \frac{z}{z_{0,1}} \ln \frac{\delta_{\mathrm{b}}(F)}{z_{0,2}}}$,

where $z_{0,1}$ is the upwind terrain surface roughness. Thus the profile remains logarithmic; however, its actual shape is calculated by two subsequent transformations.

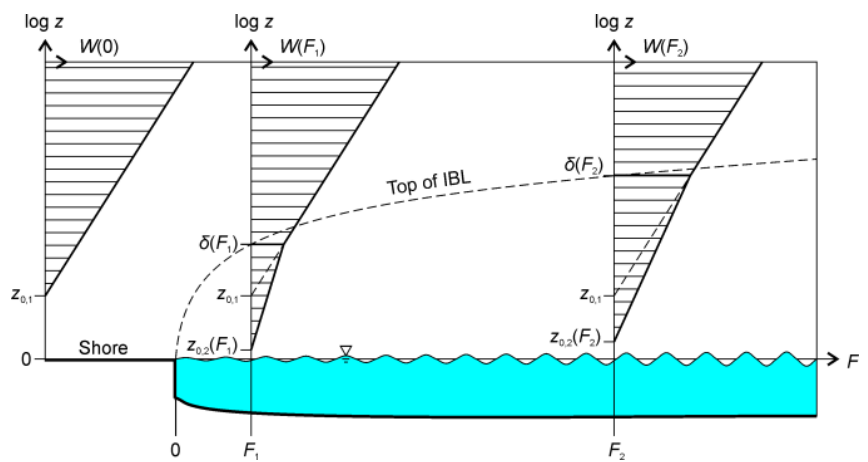

Fig. 2. Sketch of IBL development downwind of an abrupt change of roughness height at the lakeshore or reed borderline. Three consecutive vertical wind speed profiles are shown for a wind blowing from the left. The vertical axis represents the height in logarithmic scale above the water surface.

\section{Coupled modelling of the IBL and the surface wind shear stress}

A coupling between the IBL development and surface wind shear stress estimation can be established if Eq. (3) is introduced into the algorithm described by Eqs. (5-7) in an iterative way (Curto et al., 2006; Young and Verhagen, 1996). More specifically, we calculate the IBL and surface roughness heights along the fetch, given the wind speed $W_{10}$ (or transformed to that height by Eq. (2)) and the land roughness height $z_{0,1}$ using Eq. (7) with $z=10 \mathrm{~m}$ anemometer height. Values of $W_{*}, z_{0,2}$ and $\delta_{b}$ are updated in each iteration step with the intermediate $W_{10}$. Convergence is monitored by $W_{*}$.

The development of the IBL height $\delta_{b}, W_{10}$ wind speed and $\tau_{s}$ surface wind shear stress in terms of the fetch for various equilibrium $W_{10}$ wind speed at zero fetch (that is at the shoreline) were calculated as outlined above are seen in Figs. 3-5. The upwind terrain roughness $z_{0,1}$ is assumed to be $0.15 \mathrm{~m}$, a value found relevant to reed zones in Lake Neusiedl, as will be derived from the measurements. Note that $W_{10}$ changes only if the IBL height exceeds $10 \mathrm{~m}$, and also the significant though attenuating increase of the wind shear stress, both to be proved by the dual point field measurements.

\section{CALIBRATION AND VERIFICATION OF THE WIND STRESS MODEL IN FERTŐRÁKOS BAY}

Novel field measurements capturing the specific features of the above-mentioned IBL-based wind field were carried out in Fertörákos Bay in 2001. In the previous flow observations, a strong clock-wise, bay-wide circulation was often found to develop despite the fact the bay bottom is characterized by very mild slopes. Namely, at average lake water surface elevation, 
the depth in the middle part does not exceed $1.5 \mathrm{~m}$ whereas it drops to $1 \mathrm{~m}$ next to the reed border where a half a meter sudden step is observed and prevails inside the littoral zone.

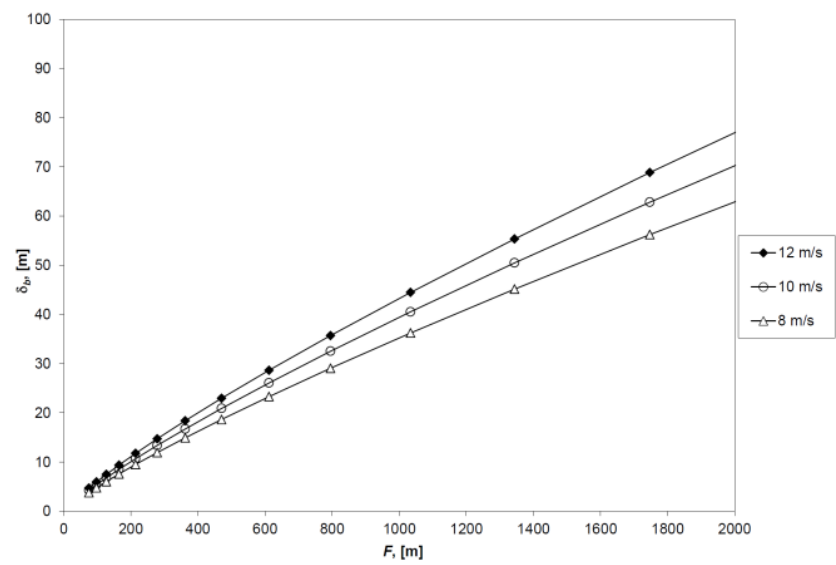

Fig. 3. IBL development over the water surface along the fetch for various $W_{10}$ equilibrium wind speeds at the shoreline; land roughness equals to $0.15 \mathrm{~m}$.

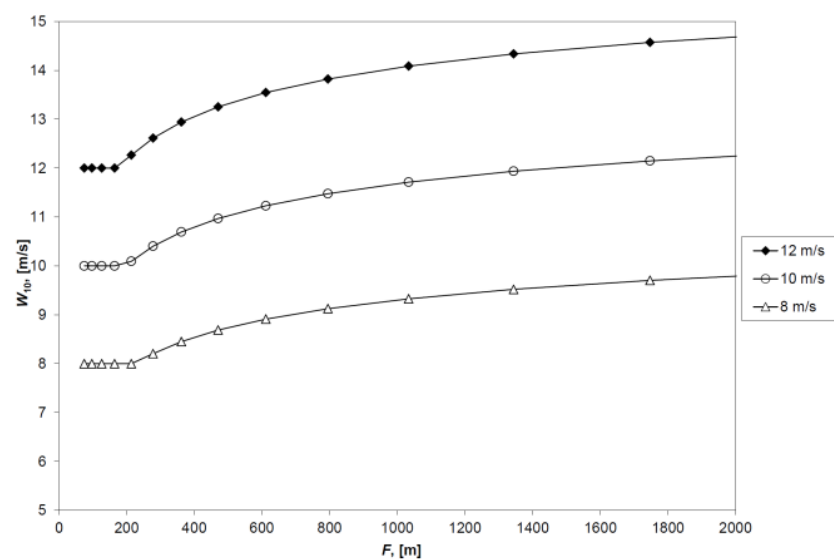

Fig. 4. Wind speed at $10 \mathrm{~m}$ height above the water surface along the fetch for various $W_{10}$ equilibrium wind speeds at the shoreline; land roughness equals to $0.15 \mathrm{~m}$.

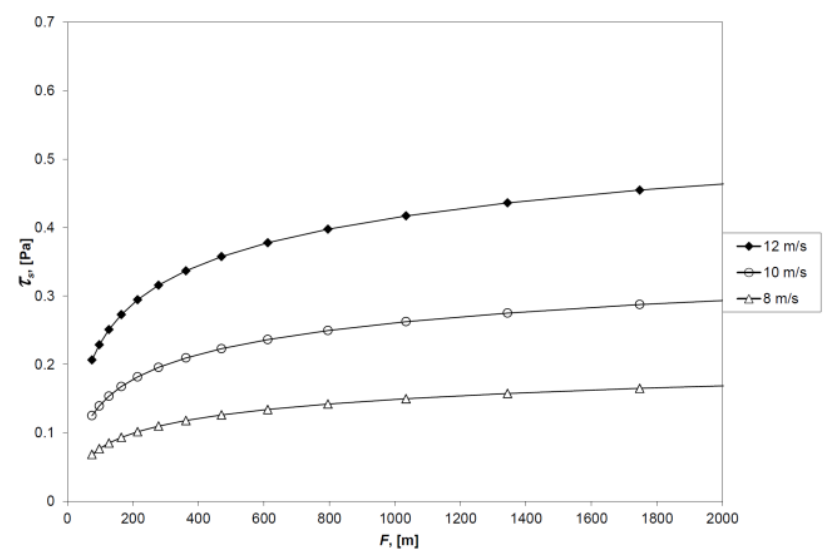

Fig. 5. Wind shear stress at the water surface along the fetch for various $W_{10}$ equilibrium wind speeds at the shoreline; land roughness equals to $0.15 \mathrm{~m}$.

In order to reveal fetch dependence, a special measurement set-up was conceived as seen in Fig. 6 measuring the wind speed along the prevailing NNW-SSE wind axis at two sites, some $1.5 \mathrm{~km}$ far from each other and a bit more than $100 \mathrm{~m}$ far from the reed border each. Reed stems were less than $3 \mathrm{~m}$ high on average in the measurement period. Upwind from the bay the several $\mathrm{km}$ wide reed belt, though patchy at places, was rather continuous, expected to give room to an equilibrium wind profile for NNW winds prevailing in the region. Standard Aanderaa wind speed and direction sensors (Aanderaa Instruments, 2000) were set at $3.3 \mathrm{~m}$ height in order to be outside the wave-disturbed layer. As it will be discussed later, also Aanderaa's RCM9 2-D acoustic Doppler current meters were deployed at both sites to measure and analyze the lake currents induced simultaneously.

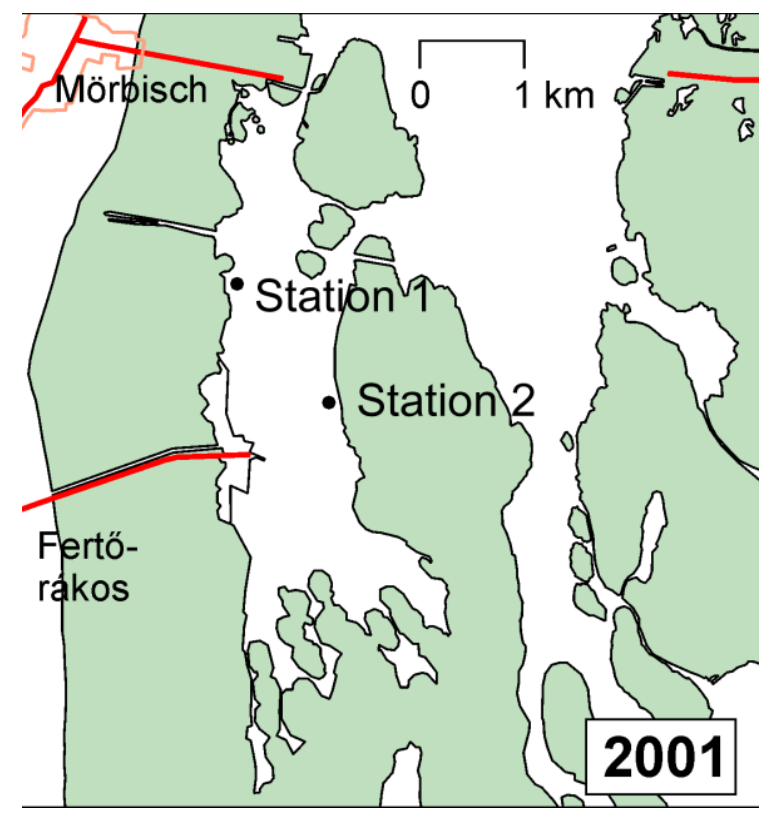

Fig. 6. Wind and flow measurement stations (indicated by dots) in 2001 deployed in Fertörákos Bay, a southwest part of Lake Neusiedl.

Wind data collected throughout May-June 2001 at the two stations were used to calibrate and verify the IBL model. Six recorded storm events coming basically from the prevailing NNW direction were considered in the analysis. Near-neutral stratification conditions were met in the measurements.

As a representative example, we first give the data for the period 3-5 May. As can be seen in Fig. 7, speeds measured at Station 2 were coherently higher due to the generally $1.5 \mathrm{~km}$ longer fetch. An agreement was required for the speeds transformed back to the upwind reed border from both wind stations. Recall that the IBL model allows us to transform wind speed vertically and along the fetch using rearranged forms of Eqs. (6) and (7). The simultaneously measured, transformed $W_{10}$ speeds corresponding to $0.15 \mathrm{~m}$ reed roughness height obtained by least-squares fitting are plotted in Fig. 8 showing reasonable agreement.

Parameter fitting for the six selected individual storm events resulted in a roughness height that varied between 0.10 and $0.18 \mathrm{~m}$ which is a narrow range compared to the ones given in relevant boundary layer meteorology textbooks for canopy types close to reed of nature. Fig. 9 shows the merged data of the six selected storm events, whereas Fig. 10 gives the speeds transformed to the reed borderline corresponding to $0.15 \mathrm{~m}$ reed roughness height clearly verifying the assumption. Anyway, reed canopy for which the aerodynamic roughness values were derived from the measurements reasonably fits literature data e.g. values characterising terrains covered by very tall grass or crops. 


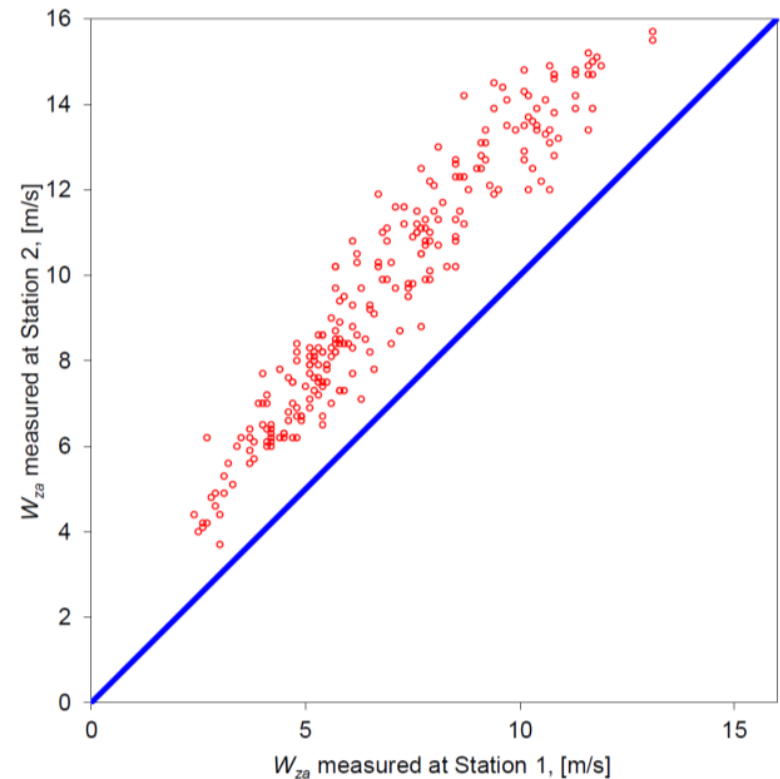

Fig. 7. Simultaneous wind speeds measured at Station 1 and Station 2 with $300-350^{\circ}(\sim \mathrm{NNW})$ direction and deviating less than $30^{\circ}$ from each other, 3-5 May, 2001.

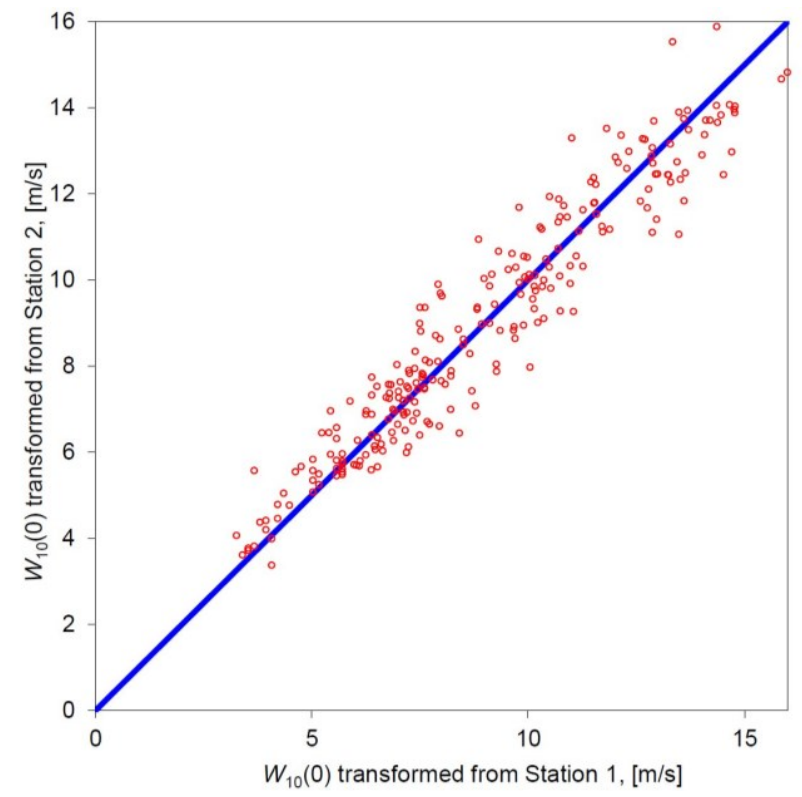

Fig. 8. Simultaneous wind speeds transformed from Station 1 and Station 2 to the upwind reed border. In both plots, perfect agreement is indicated by solid line, 3-5 May, 2001.

Overall, the IBL development in the study area proved to be a well-defined process for which the IBL model outlined here could be calibrated and verified with high confidence. Besides storms aligned with the NNW axis of the wind stations, the model was also validated with the data series of the whole, uninterrupted 27-day measurement period. The standard deviation of the wind speeds transformed back to the upwind reed border was only slightly larger than for the NNW storms showing that the IBL theory explains the wind speed difference between the two stations in a wide range of fetch configurations (Krámer, 2007). Indeed, the transformation is sensitive to the reed roughness. However, the optimal value of the roughness was not universal: it varied in the range 0.05 to $0.2 \mathrm{~m}$ depending on the directional filtering. We note that further validation is provided by Józsa et al. (2007) comparing the analytical model with atmospheric data and CFD turbulence model results for simple domains as well as for the Fertőrákos Bay.

As a major consequence of IBL-related fetch-dependent growth of the wind and resultant wind shear stress vector field in the prevailing NNW conditions is a strong clockwise curl, providing significant external vorticity source for inducing large scale circulations with the same sense of rotation. In order to see its impact, in the next chapter we will look at the vorticity form of the steady-state depth-averaged shallow water equations and briefly analyze the relative order of magnitude of the different terms.

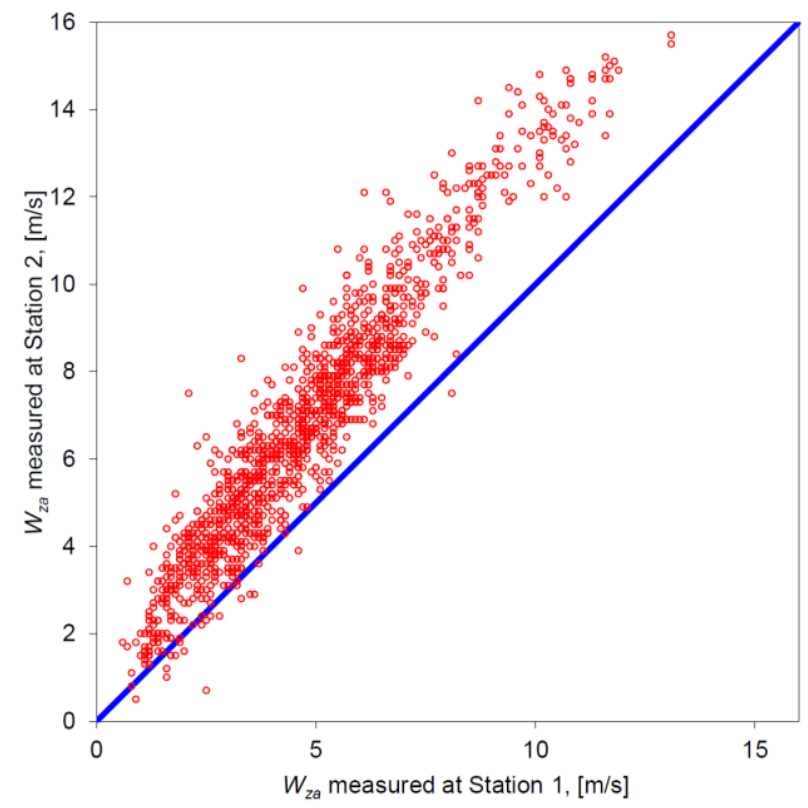

Fig. 9. Simultaneous wind speeds measured at Station 1 and Station 2 with $300-350^{\circ}(\sim \mathrm{NNW})$ direction and deviating less than $30^{\circ}$ from each other; total measurement period.

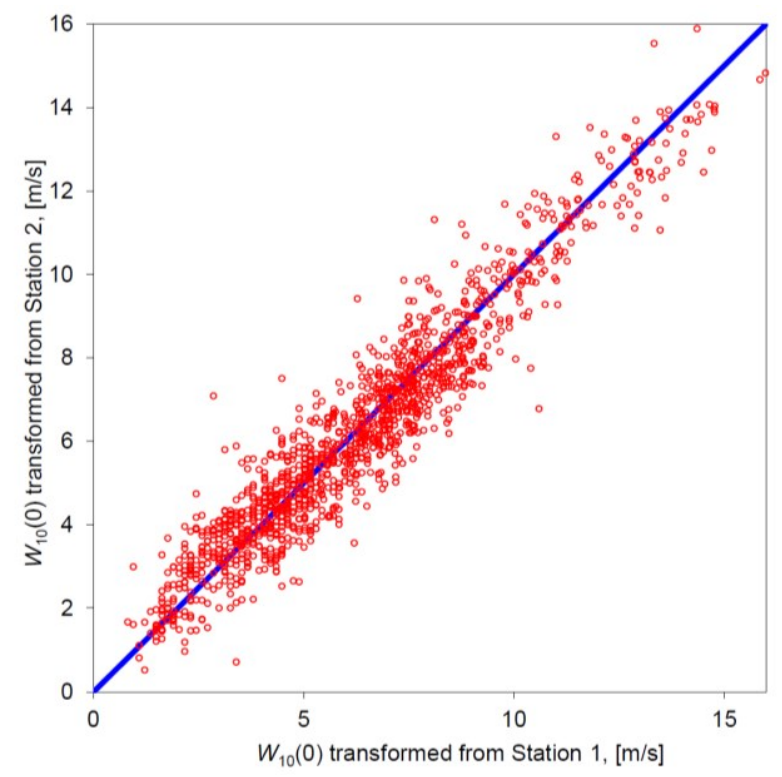

Fig. 10. Simultaneous wind speeds transformed from Station 1 and Station 2 to the upwind reed border. In both plots, perfect agreement is indicated by solid line; total measurement period. 


\section{FLOW PATTERN DUE TO THE CURL IN THE WIND SHEAR STRESS FIELD}

Though the complete description of wind-induced lake flows would require a three-dimensional approach, order of magnitude analyses prove that reasonable simplifications can be applied, nevertheless, preserving the essential of the processes, especially if the primary interest is to estimate the depth-integrated horizontal transport of water masses. The validity of such simplifications can be judged by various characteristic dimensionless and dimensional quantities (see Hutter, 1984; Simons, 1980; Shanahan et al., 1986), eventually resulting in the definition of shallow waters and applicability of their 2-D approach. Without going into details, here we note that Lake Neusiedl in general and the Fertőrákos Bay in particular fall into the category where the Coriolis effect is insignificant (that is the so-called Ekman spiral cannot develop in the velocity profile). Furthermore, the irregularities in the vertical profile of the horizontal advective velocity are efficiently damped by the vertical eddy viscosity. Consequently, the flow field can be approximated in a depthaveraged way with no significant loss of information in terms of horizontal water mass exchange compared to direct threedimensional simulations.

\section{Steady-state vorticity balance formulation of shallow lake flows}

For simplicity we assume steady-state flow conditions as a result of a prolonged constant external forcing and introduce a depth-averaged bulk horizontal momentum exchange coefficient. Based on these the depth-averaged continuity and momentum equations in an $x-y$ horizontal Cartesian coordinate system can be written as

$\nabla \cdot(\mathbf{V} h)=0$

$\mathbf{V} \cdot \nabla U=f V-g \frac{\partial \eta}{\partial x}+\frac{\tau_{s, x}}{\rho h}-\frac{\tau_{b, x}}{\rho h}+\frac{1}{h} \nabla \cdot\left(v_{e, h} h \nabla U\right)$

$\mathbf{V} \cdot \nabla V=-f U-g \frac{\partial \eta}{\partial y}+\frac{\tau_{s, y}}{\rho h}-\frac{\tau_{b, y}}{\rho h}+\frac{1}{h} \nabla \cdot\left(v_{e, h} h \nabla V\right)$,

where $\mathbf{V}$ - depth-averaged horizontal flow velocity vector with its $x$ - and $y$-component $U$ and $V$, respectively, $h$ - water depth, $\eta$ - free surface elevation reffered to still water level, $\tau_{s, x}$ and $\tau_{s, y}$ - surface wind shear stress components, $\tau_{b, x}$ and $\tau_{b, y}$ - bottom shear stress components, $f$-Coriolis coefficient, $v_{e, h}$ - effective horizontal eddy viscosity coiefficient and $\rho$-water density.

In order to analyse the vorticity balance in a wind-induced shallow flow problem and demonstrate the role of the IBLdominated wind shear stress field in it, we rewrite the shallow water governing equations to a depth-averaged vorticity transport equation, an approach similar to Laval et al., 2003; Rueda et al., 2005; Simons, 1980; and Schwab and Beletsky, 2003. Taking the curl of the system of Eqs. (9)-(10), then expanding it by applying also the continuity Eq (8), the new form is as follows:

$$
\begin{aligned}
\mathbf{V} \cdot \nabla \varsigma= & -(\varsigma+f) \frac{1}{h} \mathbf{V} \cdot \nabla h+\frac{1}{\rho h}\left(\nabla \times \tau_{s}-\frac{1}{h} \tau_{s} \times \nabla h\right), \\
& -\frac{1}{\rho h}\left(\nabla \times \tau_{b}-\frac{1}{h} \tau_{b} \times \nabla h\right)+v_{h} \nabla^{2} \varsigma
\end{aligned}
$$

where

$\varsigma=\frac{\partial V}{\partial x}-\frac{\partial U}{\partial y}=\nabla \times \mathbf{V}$, is the curl of the depth-averaged velocity and $\nabla=$ del operator $(\partial / \partial x, \partial / \partial y)$.

As a default approximation, the quadratic Manning formula is used to describe bed shear stresses with uniform Manning's roughness coefficient $n$ as follows:

$\boldsymbol{\tau}_{b}=\frac{\rho g n^{2}}{h^{1 / 3}}|\mathbf{V}| \mathbf{V}$.

Analyzing the vorticity balance from the point of view of the generation mechanism of shallow lake horizontal circulations, it is seen that the vorticity sources are in the second bracket on the right hand side (whereas sinks in the third, related to bed shear). The first term

$\frac{1}{\rho} \nabla \times \tau_{s}$,

represents the vorticity introduced to the lake by the curl of the wind shear stress field resulting from its spatial irregularity governed largely by the IBL evolution. In turn, the

$-\frac{1}{\rho h} \tau_{s} \times \nabla h$,

vorticity source expresses the combined effect of the local wind shear stress vector and the relative depth gradient. In fact, these terms have the features and resultant impact as follows:

- In case of uniform wind shear stress field, term (14) vanishes and the term (15) related to the depth gradient dominates the circulation, resulting in the formation of the wellknown barotropic topographic gyres, as explained by e.g. Simons (1980).

- In Eq. (15) bottom gradients become active vorticity source by the wind shear stress component parallel to isobaths.

- Term (15) scales inversely with the depth whereas term (14) is independent of it, consequently e.g. a lake-wide water level rise results in weakening whereas a drop in strengthening of term (15) against (14).

\section{Validation of wind-induced flows in the Fertőrákos Bay}

The mild slopes of the bottom in contrast to the strong wind stress curl in the Fertörákos Bay suggest the development of an IBL-driven significant clockwise horizontal circulation in the prevailing NNW windstorms. It is clearly reflected in Fig. 11 where the 10 min wind and simultaneously flow velocity vectors at the two measurement sites are displayed with some lowpass filtering for the period 3-5 May already used in the IBL analysis. The water depth was 1.1 and $1.2 \mathrm{~m}$ at site 1 and 2, whereas the current meter's sensor depth was 0.6 and $0.7 \mathrm{~m}$, respectively. It comes out that in the absence of significant bottom gradients, the strong imbalance in the surface wind shear stress dominates the bay-wide circulations in which water masses go with the wind in the strongly exposed downwind zone, whereas return currents occur in the upwind zone relatively poor in wind shear stress. It is striking to see the systematic difference in wind speed between the two sites, moreover, the stability of the flow in direction, nevertheless, following the large-scale variation of the wind strength and carrying oscillatory seiche components, too. Anyway, the measured flow directions fit well the clockwise circulation pattern.

The theoretical analysis and data evaluation proved that topographic gyres due to relative depth gradients can be significantly modified, counterbalanced or even reversed by the curl of the wind shear stress field. The weight of the two main vorticity sources for the same winds can be then further modified by changes of the lake water level, moreover, by the change of the 
roughness height on the upwind lakeshore, influencing the IBL development.

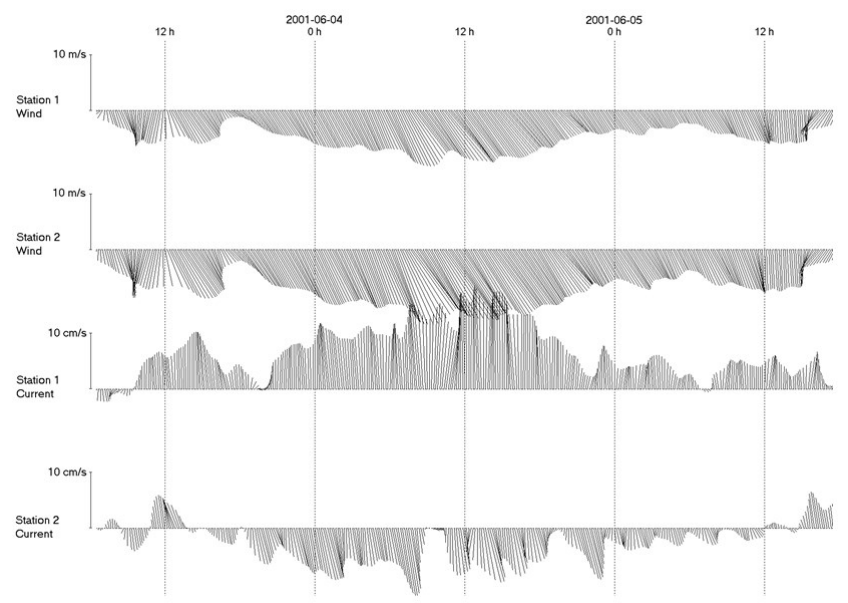

Fig. 11. Vector time series of a prevailing storm event. Harmonics with less than 1 hour time period removed.

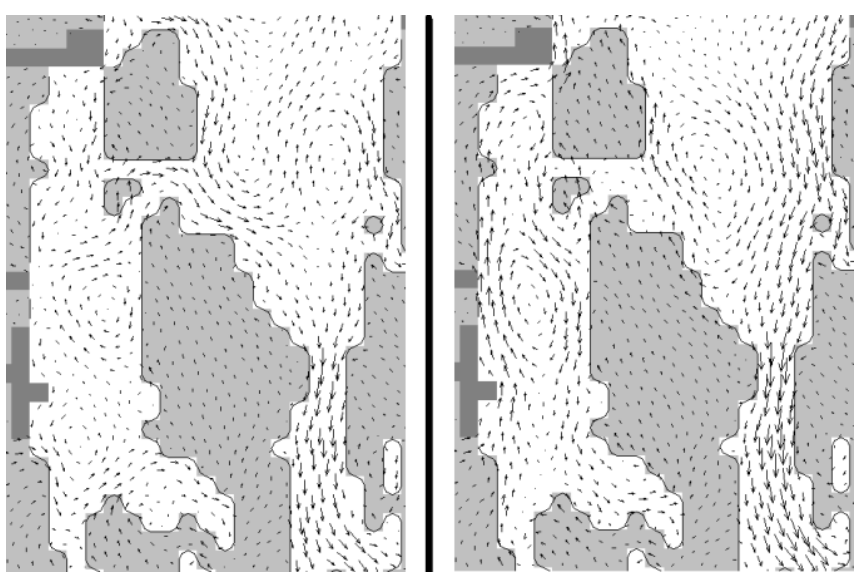

Fig. 12. Left panel: Modelled steady-state flow pattern, induced by a wind shear stress field uniform over the pelagic areas, corresponding to $W_{10}=13 \mathrm{~m} / \mathrm{s} \mathrm{NNW}$ wind. Highest velocities in the study bay are around $6 \mathrm{~cm} / \mathrm{s}$. Right panel: Modelled steady-state flow pattern, induced by a wind shear stress field according to the IBL development, corresponding to $W_{10}=12 \mathrm{~m} / \mathrm{s}$ NNW wind and $0.15 \mathrm{~m}$ roughness height at the upwind reed border. Highest velocities in the study bay around $12 \mathrm{~cm} / \mathrm{s}$.

At last, a simple 2-D, in-house explicit finite difference flow model (Krámer et al., 2000) solving the unsteady form of Eqs. (8)-(10) on a Cartesian equidistant Arakawa $\mathrm{C}$ grid was also supplied with the presented IBL module and applied to validate the above findings. A $200 \mathrm{~m}$ cell size grid was used in the calculations and no further calibration for the IBL-based wind shear stress field was needed. Instead, the roughness coefficients $n$ of the pelagic areas and inside the reed were subjects to tuning, resulting in 0.025 and $0.15 \mathrm{~s} / \mathrm{m}^{1 / 3}$ values, respectively. As to the wind effect on the reed-covered zones, it was entirely disregarded due to the high reed stem density. The difference between the steady-state flow patterns corresponding to constant wind stress (Fig. 12 left panel) scaled by a drag coefficient suggested by Wu (1982), and IBL-dependent wind shear stress field (Fig. 12 right panel) is striking. While in the former no pronounced bay-wide circulation develops due to the gentle depth gradients and the lack of the curl in the wind shear stress field, in the latter the large scale clockwise circulation is dominant and very close to what was measured in situ. Looking at the upper right part of this Figure, it is seen that, not surprisingly, the same sense of circulation also develops in that zone of the lake as its exposure to the wind is basically the same as the one of the study bay. In turn, the straights leading to the large southern lake zones (lower right part in the figure) are characterized by rather unidirectional through-flow compensated by the counter-flow in the wind-sheltered reed-covered areas.

\section{SUMMARY AND CONCLUSIONS}

It was proved that the wind stress curl as an external vorticity source plays an important role in shaping large scale lake circulations. The analysis of purpose-oriented simultaneous wind and current measurements data collected in the Hungarian part of Lake Neusiedl reasonably fitted the IBL development theory over the lake surface. A 2-D vorticity formulation of wind-induced flows was used to mathematically demonstrate the IBL-related large scale circulation generation mechanism then well reflected in the measured data. Further validation of the findings was carried out by means of simple 2-D numerical flow modeling in which details on the flow pattern, besides the measurement sites, could be also revealed. Wind-induced lake circulations linked to IBL development shows, in fact, a novelty and should be implemented in up-to-date numerical flow models. In the light of present time awareness on the hydrological consequences of climatic change (Balek, 2006), the outlined approach could also more realistically predict e.g. the modification of circulation patterns and related transport tendencies due to significant drops of lake water levels.

Acknowledgements: This work is connected to the "Development of quality-oriented and harmonized $\mathrm{R}+\mathrm{D}+\mathrm{I}$ strategy and functional model at BME" project, and supported by the New Széchenyi Plan (Project ID: TÁMOP-527 4.2.1/B-09/1/KMR2010-0002).

List of symbols

$c_{10} \quad-$ aerodynamic drag coefficient [-] related to wind speed at $10 \mathrm{~m}$,

$f^{-} \quad$ Coriolis coefficient $\left[\mathrm{T}^{-1}\right]$,

$F \quad-$ wind fetch [L],

$g \quad-$ acceleration due to the gravity $\left[\mathrm{LT}^{-2}\right]$,

$h \quad-$ water depth [L],

$U, V$ - depth-averaged velocity components in $x$ and $y$ direction, respectively $\left[\mathrm{LT}^{-1}\right]$,

V - depth-averaged horizontal flow velocity vector $\left[\mathrm{LT}^{-1}\right]$,

$W(z) \quad-$ horizontal wind speed $\left[\mathrm{LT}^{-1}\right]$ at elevation $z$,

$W_{z a} \quad-$ horizontal wind speed $\left[\mathrm{LT}^{-1}\right]$ at $z_{a}$ anemometer height,

$W_{10} \quad$ - horizontal wind speed $\left[\mathrm{LT}^{-1}\right]$ at $10 \mathrm{~m}$ height,

$W_{*} \quad-$ wind friction velocity $\left[\mathrm{LT}^{-1}\right]$,

$x, y, z$ - Cartesian horizontal and vertical space coordinates [L], respectively,

$z_{a} \quad-$ wind anemometer height [L],

$z_{0} \quad-$ aerodynamic roughness height [L],

$z_{0,1} \quad-$ upwind terrain or reed roughness height $[\mathrm{L}]$,

$z_{0,2} \quad-$ lake surface roughness height [L],

$\alpha \quad-$ Charnock's parameter [-],

$\delta_{\mathrm{b}} \quad-$ internal boundary layer height [L],

$\zeta-$ curl of the depth-averaged flow velocity vector field $\left[\mathrm{T}^{-1}\right]$,

$\eta \quad-$ free surface elevation reffered to still water level [L],

$\kappa \quad-$ von Kármán constant [-], 


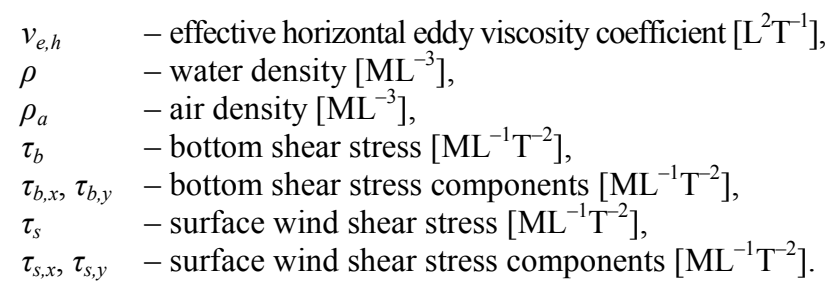

\section{REFERENCES}

Aanderaa Instruments, 2000. Product Catalogue, Bergen, Norway.

Balek, J., 2006. Hydrological consequences of the climatic changes. J. Hydrol. Hydromech., 54, 4, 357-370.

Charnock, H., 1955. Wind stress on a water surface. Quarterly J. Royal Meteorological Society, 81, 639-640.

Curto, G., Józsa, J., Napoli, E., Krámer, T., Lipari, G., 2006. Large scale circulations in shallow lakes. In: Brocchini, M., Trivellato, F., (Eds.): Vorticity and turbulence effects in fluid structure interactions. WIT Press, Southampton, UK, 83-104.

Elliott, W.P., 1958. The growth of the atmospheric internal boundary layer. Trans. Am. Geophys. Union, 39, 1048-1054.

Hutter, K., 1984. Fundamental equations and approximations. In: Hutter, K., (Ed.): Hydrodynamics of lakes, Courses and Lectures - No. 286, Springer Verlag, Wien - New York, $1-38$.

Józsa, J., Milici, B., Napoli, E., 2007. Numerical simulation of internal boundary-layer development and comparison with atmospheric data. Boundary-Layer Meteorology, 123, $159-175$.

Józsa, J., Sarkkula, J., Tamsalu, R., 1990. Calibration of modelled shallow lake flow using wind field modification. Proc. VIII. International Conference on Computational Methods in Water Resources, Venice, Italy, 1990, CMP/Springer, 165-170.

Józsa, J., Rákóczi, L., Sarkkula, J., Krámer, T., Kuusisto, M., 1998. Recent development in hydro- and sediment dynamics research of shallow Hungarian Lakes. CD-ROM Proc. 3rd International Conference on Hydro-Science and Engineering, Cottbus, Germany, 1998, The University of Mississippi, Center for Comput. Hydro-Science and Engineering, 1998.

Józsa, J., Sarkkula, J., Krámer, T., 1999. Wind induced flow in the pelagic zones of Lake Neusiedl. CD-ROM Proc. XXVIII. IAHR Congress, Graz, Austria, 22-27 August, 1999, Technical University Graz.

Krámer, T., 2007. Solution-adaptive 2D modelling of windinduced lake circulation. Ph.D. thesis, Budapest University of Technology and Economics, Hungary.
Krámer, T., Józsa, J., Sarkkula, J., 2000. Modelling of a coastal wetland for restoration planning. CD-ROM Proc. International Symposium on Restoration of Lakes and Wetlands, Bangalore, India.

Laval, B., Imberger, J., Hodges, B.R., Stocker, R., 2003. Modeling circulation in lakes: Spatial and temporal variations. Limnol. Oceanogr., 48, 3, 983-994.

Podsetchine, V., Schernewski, G., 1999. The influence of spatial wind inhomogeneity on flow patterns in a small lake. Water Research, 33, 15, 3348-3356.

Rao, A.R., Kumar, B., 2008. Estimating bed shear from velocity profile. J. Hydrol. Hydromech., 56, 1, 14-22.

Rueda, F.J., Schladow, G., Monismith, S.G., Tacey, M.T., 2005. On the effects of topography on wind and the generation of currents in a large multi-basin lake. Hydrobiologia, 532, 139-151.

Sarkkula, J., Józsa, J., Bakonyi, P., 1991. Measuring and modelling wind induced flow in shallow lakes. In: Hydrology of Natural and Manmade Lakes, Proc. Vienna Symposium, IAHS Publication 206, 219-226.

Savelyev, S.A., Taylor, P.A., 2001. Notes on internal boundarylayer height formula. Boundary-Layer Meteorology, 101, 293-301.

Schwab, D., Beletsky, D., 2003. Relative effects of wind stress curl, topography, and stratification on large-scale circulation in Lake Michigan. J. Geophys. Res., 108, C2, 3044-3053.

Shanahan, P., Harleman, D.R.F., Somlyódy, L., 1986. Windinduced Water Motion. In: van Straten, G., Somlyódy, L., (Eds.): Modeling and Managing Shallow Lake Eutrophication, Springer, Berlin, 204-255.

Simons, T.J., 1980. Circulation models of lakes and inland seas. Canadian Bulletin of Fisheries and Aquatic Sciences, 203, Ottawa, Canada.

Stull, R.B., 1991. An introduction to boundary layer meteorology. Kluwer Publishing.

Taylor, P.A., Lee, R.J., 1984. Simple guidelines for estimating wind speed variations due to small scale topographic features. Climatologic Bulletin, Canadian Meteorological and Oceanographic Society, 18, 2, 3-32.

Walmsley, J.L., 1989. Internal boundary layer height formulae - a comparison with atmospheric data. Boundary-Layer Meteorology, 47, 251-262.

Wu, J., 1982. Wind-stress coefficients over sea surface from breeze to hurricane. J. Geophys. Res., 87, C12, 9704-9706.

Young, I.R., Verhagen L.A., 1996. The growth of fetch limited waves in water of finite depth. Part 1. Total energy and peak frequency. Coastal Eng., 29, 47-78.

Received 30 April 2012 Accepted 18 October 2013 